\title{
Evaluation of the Masticatory Part and the Habitual Chewing Side by Wax Cube and Bite Force Measuring System (Dental Prescale ${ }^{\circledR}$ )
}

\author{
Mutsumi Takahashi, DDS, Fumi Takahashi, DDS, PhD, and Osami Morita, DDS, PhD \\ Department of Complete Denture, The Nippon Dental University School of Life Dentistry at Niigata, Japan
}

\section{Clinical significance}

The results of this study suggest that the determination of the masticatory part by clenching the test food and the evaluation of the occlusal contact area, occlusal force, and the center of the occlusal balance by Dental Prescale were useful to determine the habitual chewing side.

\begin{abstract}
Purpose: This study evaluated the masticatory side as well as which side was the habitual chewing side by the use of wax cubes and a bite force measuring system in normal dentate subjects (ND) and complete denture wearers (CD).

Methods: Forty two ND subjects (29 males, 13 females; mean age, $24.8 \pm 2.4$ years), and 11 CD subjects (4 males, 7 females; mean age, $72.8 \pm 7.0$ years) participated in the study. The test food used in this study was wax cubes to determine the masticatory side. The difference in the occlusal contact area and occlusal force between the masticatory side and the opposite side was investigated using Dental Prescale ${ }^{\circledR}$. ND was classified into 2 groups: those whose agreement on the masticatory part was high (ND-H) or low (ND-L). The distribution of the center of the occlusal balance was analyzed by Dental Prescale $^{\circledR}$ in ND-H, ND-L, and CD.

Results: The occlusal contact area and occlusal force of the masticatory side was greater than the opposite one, and the center of the occlusal balance was wide in ND-H. In ND-L and CD, the occlusal contact area and occlusal force did not differ between the masticatory side and the opposite one, and the center of the occlusal balance developed a tendency to gather in the center.

Conclusion: The results of this study suggested that the evaluation of the masticatory side and the use of Dental Prescale were helpful in determining the habitual chewing side.
\end{abstract}

Key words: masticatory part, habitual chewing side,

\footnotetext{
Corresponding to: Dr Mutsumi Takahashi

Department of Complete Denture, The Nippon Dental

University School of Life Dentistry at Niigata

1-8 Hamaura-cho, Chuo-ku, Niigata 951-8580, Japan

Tel: +81-25-267-1500, Fax: +81-25-267-8906

E-mail: mutsumit@ngt.ndu.ac.jp
}

Received on January 10, 2008/Accepted on May 21, 2008 bite force measuring system, wax cube

\section{Introduction}

Mastication is a series of the process of chewing food for swallowing and digestion. There have been many methods to examine the functions of ingestion, crunching, comminution, mixing, formation of bolus, and swallowing.

There are two types of methods to examine the ability of mastication. One of the methods to examine the ability of mastication is to masticate a test food directly. The test food differs according to the type of ability of mastication that would be evaluated. Regarding the ability of comminution, the test foods include peanuts, raw rice etc. ${ }^{1-4}$ Concerning the ability of mixing, the test foods include chewing gum, gummy jelly etc. ${ }^{5-10} \mathrm{Al}$ so, the test food included a temporary stopping to evaluate the relationship between the occlusal contact area and the main occluding area. ${ }^{11-13}$ Other methods examined the ability of mastication from other factors involved, such as muscle activity during mastication, jaw movement, food intake questionnaire method, occlusal contact area, and occlusal force. A pressure sensitive film, inspection of gnathic function, etc have also been used to examine the ability of mastication. ${ }^{2,14-20}$

It has been reported that the ability of mastication is influenced by the intraoral environment as well as other physiological alterations such as the growth process. The habit to masticate at more useful side to crunch is developed through repeated adaptation. ${ }^{21}$ There have been various studies that reported the relating factors to the habitual chewing side, that is, the habitual chewing side was related to the path of masticatory movement, masticatory rhythm, occlusion, and the dominant hand. ${ }^{22-30}$

In general, the method to investigate the habitual chewing side is through a medical interview, ${ }^{31-33}$ however, there are some cases when the subjects 
cannot recognize the chewing side. In these cases, there are some methods to evaluate the chewing side objectively and easily in clinic, using a cotton roll, ${ }^{28,33,34}$ wax ${ }^{35-41}$ and temporary stopping. ${ }^{11-13}$ The part that these test foods were clenched was defined as the masticatory part, and the side of the masticatory part was decided to be the habitual chewing side. However, the condition of the test food such as the si ze or the hardness to decide the masticatory side in normal dentate subjects and complete denture wearers has not been investigated.

The aim of this study was to investigate the influence of the temperature conditions or the size of the wax cube as the test food to determine the masticatory part. Additionally, the relations among the masticatory part, the habitual chewing side, and occlusion was investigated using a bite force measuring system.

\section{Materials and Methods}

\section{Experiment 1}

\section{1) Subjects}

The subjects of this study were 12 healthy adults (6 males, 6 females; mean age, $26.5 \pm 2.5$ years), who had normal occlusion. The study was performed with the approval of the ethics committee of The Nippon Dental University School of Life Dentistry at Niigata (\#119), and informed consent was obtained from all of the subjects before the start of the study.

\section{2) Determining the masticatory part and method of analysis}

In this study, we used a wax cube (Inoue Attachment, Co., Tokyo, Japan) as the test food to evaluate the masticatory part. The size of the test food was a $3.5-\mathrm{mm}$ cube (about $0.04 \mathrm{~g}$ ) and a $5.0-\mathrm{mm}$ cube (about $0.10 \mathrm{~g}$ ), and the temperature conditions were 16,26 , and $36^{\circ} \mathrm{C}$.

To investigate the masticatory part, the wax cube was positioned on the center of the tongue. Subsequently, the subjects were instructed to clench the test food in 1 stroke where the subjects felt the easiest to clench the wax cube. The test was repeated 3 times on each size and each temperature condition. The clenched test food was fitted into a plaster cast that was prepared before the test (Fig. 1). The masticatory part was determined with a plaster cast with the conformed test food.

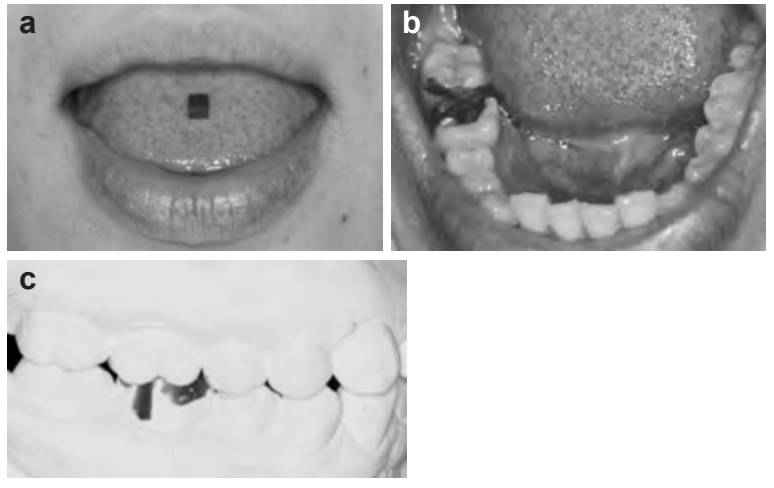

Fig. 1 a: The test food positioned on the tongue, b: Clenching the test food in 1 stroke, c: Clenched test food fitted into a plaster cast.

Then, the number of times that each subject clenched the test food at the same cusp and same marginal ridge was counted, and used for analysis. The part that the subject clenched the test food most was decided as the masticatory part. The difference in the number of agreements of the masticatory part according to the temperature conditions was analyzed by the Kruskal-Wallis test.

\section{Experiment 2}

\section{1) Subjects}

The subjects were 42 healthy adults (29 males, 13 females; mean age, $24.8 \pm 2.4$ years), who had normal occlusion (ND), and 11 healthy adults (4 males, 7 females; mean age, $72.8 \pm 7.0$ years), and who visited Niigata Hospital and wore complete dentures with no detriment (CD). The study was performed with the approval of the ethics committee of The Nippon Dental University School of Life Dentistry at Niigata (\#119), and informed consent was obtained from all of the subjects before the start of the study.

\section{2) Determination of the masticatory part and method of analysis}

In experiment 2, we also used wax cubes as the test food. The size of the test cube was $3.5 \mathrm{~mm}$ and 5.0 $\mathrm{mm}$ in $\mathrm{ND}$, and $3.5 \mathrm{~mm}, 5.0 \mathrm{~mm}$, and $8.0 \mathrm{~mm}$ (about $0.22 \mathrm{~g}$ ) in CD (Fig. 2), at room temperature.

The subjects clenched the test food in 1 stroke where the subjects felt the easiest to clench the cube. The test was repeated 5 times in ND, and 3 times in CD. The clenched test food was fitted into a plaster cast that was previously prepared. The masticatory part was determined with a plaster cast with the conformed test food. Then, the number of times that each subject clenched the test food 


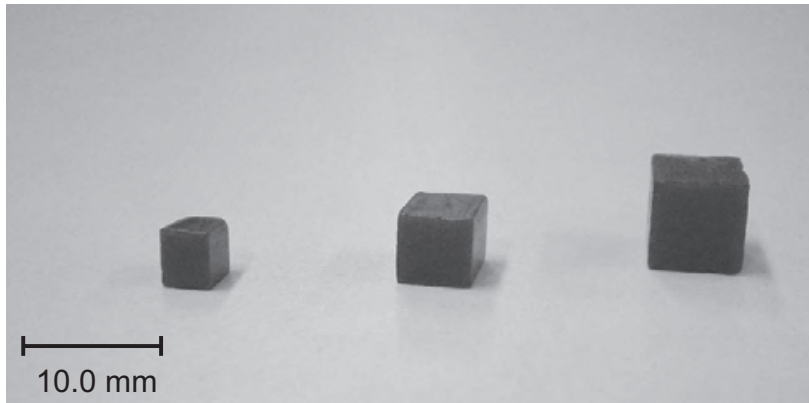

Fig. 2 Wax cubes.

at the same cusp and same marginal ridge was counted, and used for analysis. The part that the subject clenched the test food most was decided as the masticatory part. The difference in the number of agreements of the masticatory part according to the size was analyzed by the Wilcoxon signedranks test and Kruskal-Wallis test.

\section{3) Evaluation of the habitual chewing side}

The habitual chewing side was determined according to the subjectivity of each subject that was found at the time of the medical interview before mastication. The rate of agreement between the habitual chewing side and the side containing the masticatory part was calculated.

\section{4) Measurement of the occlusal contact area and occlusal force}

The occlusal contact area and occlusal force were measured using pressure sensitive film (Dental Prescale $^{\circledR} 50 \mathrm{H}-\mathrm{R}$ type, Scimolex, Co., Yamanashi, Japan), and evaluated using an Occluzar ${ }^{\circledR}$ (Fuji Film, Co., Tokyo, Japan).

The subjects bit down on the Dental Prescale for 3 seconds with maximum occlusal force. The measurement was repeated 3 times, and the average of the occlusal contact area and occlusal force was used for analysis.

\section{5) Relationship between the masticatory part,} the occlusal contact area, and occlusal force

The ND subjects were divided into 2 groups. The total number of clenching times of the wax cube in this study was 10 times ( 2 conditions by 5 times). One group consisted of 22 subjects, who had the same masticatory part more than 8 times (ND-H). The other group consisted of 20 subjects, who had the same masticatory part less than 7 times (ND$\mathrm{L})$. The side that contained the masticatory part was determined as the masticatory side, and the

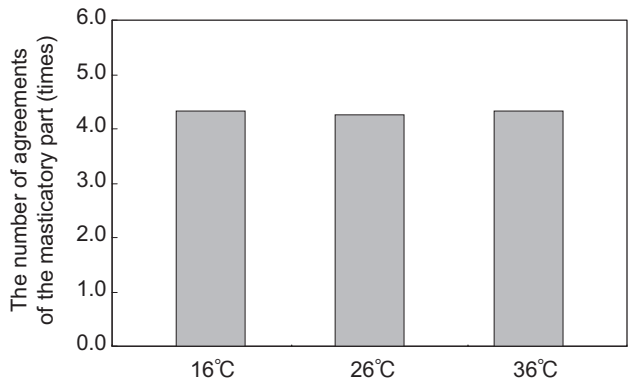

Fig. 3 The number of agreements of the masticatory part (comparison by the temperature conditions of the test food).

other side was determined as the opposite side. The total of either side was set at $100 \%$, and the percentage of the occlusal contact area and occlusal force on the masticatory side and the opposite side was calculated. The difference of the occlusal contact area and occlusal force between the masticatory side and the opposite side was analyzed by the t-test.

In the same way, the difference of the occlusal contact area and occlusal force between the masticatory side and opposite side was analyzed by the Wilcoxon signed-ranks test and t-test in CD.

\section{6) The distribution of the center of the occlusal balance}

The distribution of the center of the occlusal balance was analyzed by the results of the Dental Prescale test in ND-H, ND-L, and CD. The differences of the distribution between ND-H and ND-L were analyzed by the Mann-Whitney's U test.

\section{Results}

\section{Experiment 1}

The average of the number of agreements of the masticatory part at the temperature conditions of the wax cubes of 16,26 , and $36^{\circ} \mathrm{C}$ was $4.33 \pm 1.43$ times, $4.25 \pm 2.00$ times, and $4.33 \pm 1.54$ times, respectively. There was no statistically significant difference among the three temperature conditions of the wax cubes (Fig. 3).

\section{Experiment 2}

\section{1) Comparison by the size of the test food}

The average of the number of agreements of the masticatory part at the size of the wax cubes of 3.5 $\mathrm{mm}$ and $5.0 \mathrm{~mm}$ in ND was $3.79 \pm 1.00$ times and $3.91 \pm 1.02$ times, respectively. There was no statistically significant difference between the sizes 

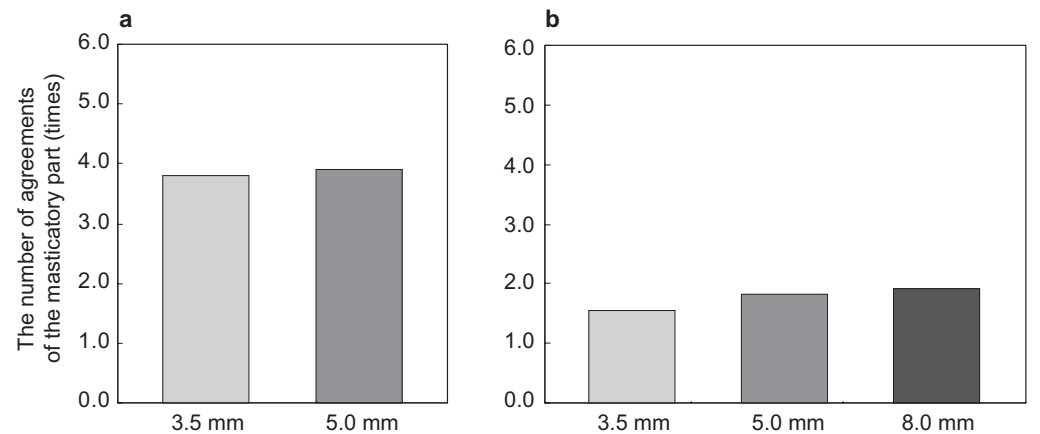

Fig. 4 a: The number of agreements of the masticatory part [comparison by the size of the test food in normal dentate subjects (ND)], b: The number of agreements of the masticatory part [comparison by the size of the test food in complete denture wearers (CD)].
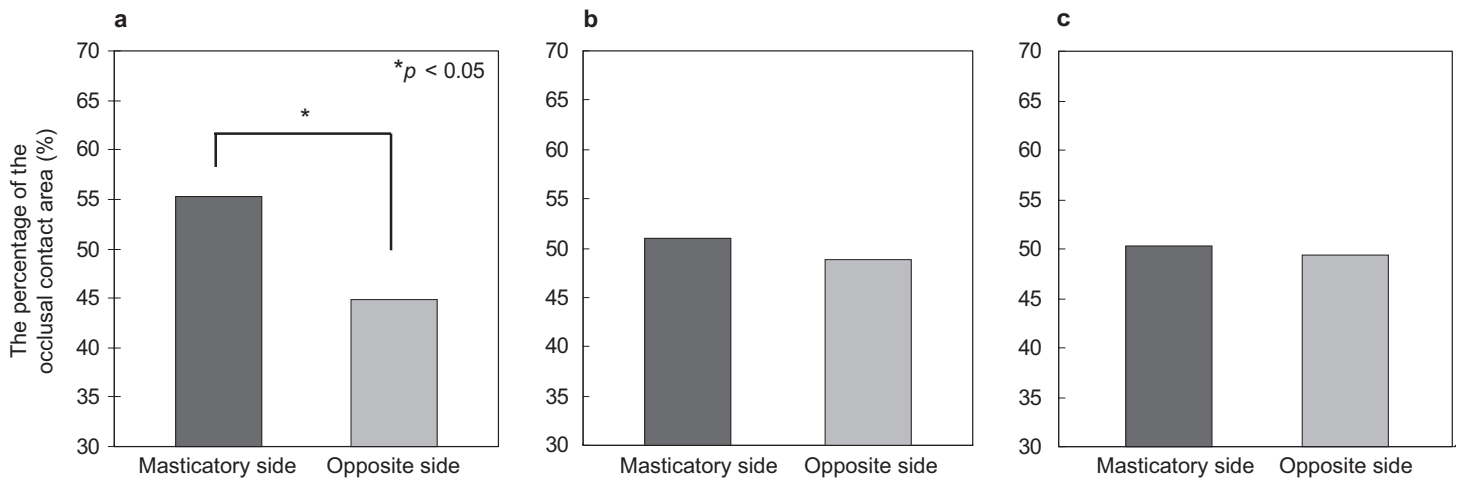

Fig. 5 a: The percentage of the occlusal contact area in normal dentate subjects who had high agreement regarding the masticatory part (ND-H), b: The percentage of the occlusal contact area in normal dentate subjects who had low agreement regarding the masticatory part (ND-L), c: The percentage of the occlusal contact area in complete denture wearers (CD).

of the test food (Fig. 4-a). Also the average of the number of agreements of the masticatory part at the size of the wax cubes of $3.5 \mathrm{~mm}, 5.0 \mathrm{~mm}$, and $8.0 \mathrm{~mm}$ in CD was $1.55 \pm 1.29$ times, $1.82 \pm 1.25$ times, and $1.91 \pm 1.04$ times, respectively. There was no statistically significant difference among the three sizes of the wax cubes (Fig. 4-b).

\section{2) The rate of agreement of the habitual chewing side and the masticatory side}

The percentage of agreement upon the habitual chewing side and the masticatory side was $95.2 \%$ (40/42 subjects) in ND and 90.9\% (10/11 subjects) in CD.

\section{3) Comparison of the occlusal contact area and occlusal force on the masticatory side and opposite side}

(1) The occlusal contact area

The results of the evaluation by the Dental Prescale test was that the percentage of the occlusal contact area of the masticatory side was greater than the opposite one in ND-H $(p<0.05)$, the average of the percentage of the occlusal contact area of the masticatory side and the opposite one was $55.2 \pm 8.5 \%$ and $44.8 \pm 8.6 \%$, respectively (Fig. 5 -a). The average of the percentage of the occlusal contact area of the masticatory side and the opposite one in ND-L was $51.0 \pm 7.0 \%$ and $49.0 \pm 7.0 \%$, respectively. There was no significant difference between the masticatory side and the opposite one (Fig. 5-b). Also, the average of the percentage of the occlusal contact area of the masticatory side and the opposite one in CD was $50.4 \pm 9.6 \%$ and $49.6 \pm 9.7 \%$, respectively. There was no significant difference between the masticatory side and the opposite one (Fig. 5-c).

(2) The occlusal force

The results of the evaluation by Dental Prescale was that the percentage of the occlusal force of the masticatory side was greater than the opposite one in ND-H $(p<0.05)$, the average of the percent- 

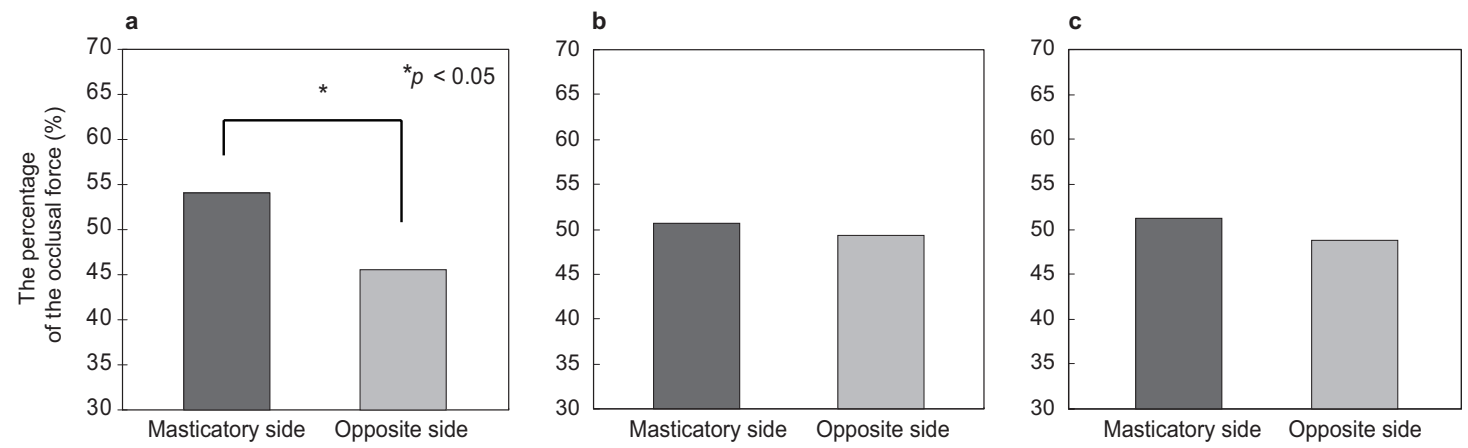

Fig. 6 a: The percentage of the occlusal force in normal dentate subjects who had high agreement regarding the masticatory part (ND-H), b: The percentage of the occlusal force in normal dentate subjects who had low agreement regarding the masticatory part (ND-L), c: The percentage of the occlusal force in complete denture wearers $(\mathrm{CD})$.

a

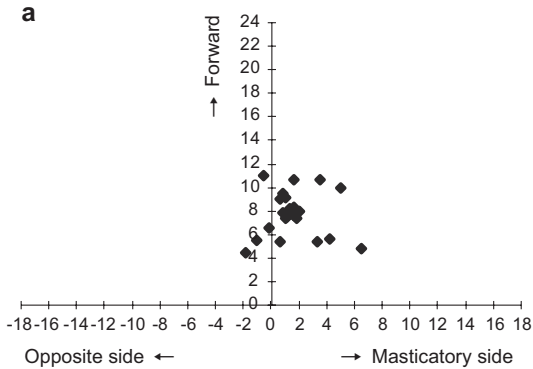

b

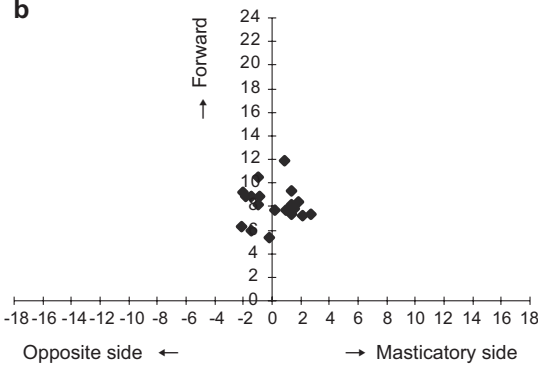

c

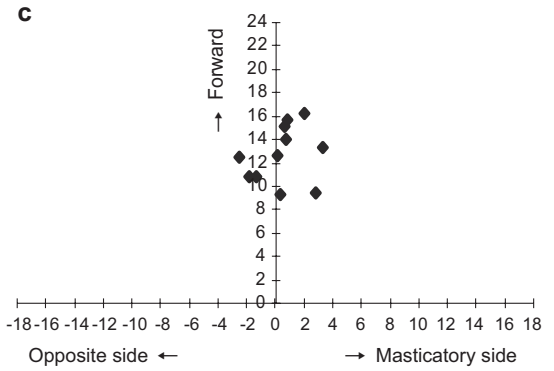

Fig. 7 a: The distribution of the center of the occlusal balance in normal dentate subjects who had high agreement regarding the masticatory part (ND-H), b: The distribution of the center of the occlusal balance in normal dentate subjects who had low agreement regarding the masticatory part (ND-L), c: The distribution of the center of the occlusal balance in complete denture wearers $(\mathrm{CD})$.

age of the occlusal force of the masticatory side and the opposite one was $54.0 \pm 7.4 \%$ and $46.0 \pm 7.2 \%$, respectively (Fig. 6-a). The average of the percentage of the occlusal force of the masticatory side and the opposite one in ND-L was $50.7 \pm 6.8 \%$ and 49.3 $\pm 6.8 \%$, respectively. There was no significant difference between the masticatory side and the opposite one (Fig. 6-b). Also, the average of the percentage of the occlusal force of the masticatory side and the opposite one in CD was $51.2 \pm 9.0 \%$ and $48.8 \pm 9.0 \%$, respectively. There was no significant difference between the masticatory side and the opposite one (Fig. 6-c).

\section{4) The distribution of the center of the occlusal balance}

The distribution of the center of the occlusal balance in ND-H, ND-L, and CD is shown in Fig. 7. The distribution of the center of the occlusal balance in ND-H was wider than ND-L in bilateral distribution $(p<0.05)$.

\section{Discussion}

\section{The test food}

In the present study, we selected wax cubes as the test food to evaluate the masticatory part. Kato et al. ${ }^{11,12}$ and Tokuda et al. ${ }^{13}$ used a temporary stopping for normal dentate subjects. However, the temporary stopping was too difficult to clench for complete denture wearers. Ichikawa et al. ${ }^{37}$ used clearance wax (Syofu Inc., Kyoto, Japan) for complete denture wearers. The wax cube used in this study was made by mixing paraffin wax with $\mathrm{Hi}^{-}$ Mic-1045 wax. $^{35,36,38-41}$ It can be used widely for normal dentate subjects and complete denture wearers, because it does not stick to the teeth or dentures. The wax cube can be fabricated in any size and the temperature conditions can vary; therefore, the complete denture wearers probably clenched the wax cube easily. Therefore it can evaluate objective data in a short time, and the subjects were not burdened with this evaluation. 
For these reasons, the wax cube was selected as the test food in this study.

In experiment 1 , the proper temperature conditions of the test food to determine the masticatory part was investigated in normal dentate subjects. According to the results of questions to the subjects, the subjects could clench the test food the easiest at the temperature condition of $26^{\circ} \mathrm{C}$. There was no relationship between the subjectivity of easily clenching and the determination of the masticatory part. This study suggested that the hardness of the test food did not influence the determination of the masticatory part, because there was no difference in the number of agreements of the masticatory part among the temperature conditions. Therefore, it was suggested that controlling the temperature conditions of the test food was not necessary.

\section{The masticatory part}

In experiment 2, the test was repeated 5 times in $\mathrm{ND}$, and 3 times in CD, because the importance of one trial was large at the case of the comparison by 2 sizes of the test food on 3 trials in ND. The subjects clenched the test food with the size of $3.5 \mathrm{~mm}$ more easily than $5.0 \mathrm{~mm}$ in ND, but there was no relationship between the subjectivity of easily clenching and the determination of the masticatory part. On the other hand, the subjects felt that it was most difficult to clench the test food with the size of $3.5 \mathrm{~mm}$ in $\mathrm{CD}$, and some of them clenched the test food using the anterior teeth or the test food fell from the occlusal surface. Therefore, it was suggested that the test food with the size of $3.5 \mathrm{~mm}$ was not suitable to determine the masticatory part in CD. According to the results of questions to the subjects, the subjects clenched the test food easily with the size of $5.0-\mathrm{mm}$ and $8.0-\mathrm{mm}$ cubes in CD, but there was no relationship between the subjectivity of easily clenching and determination of the masticatory part. These results suggested that the size of the test food did not influence the determination of the masticatory part.

\section{Relationship between the subjectivity of the habitual chewing side and the masticatory side} Regarding the frequency of the subjectivity of the habitual chewing side, Ueda et al. ${ }^{42}$ reported that about half of the subjects were conscious of their habitual chewing side, and Kurachi et al. ${ }^{31}$ reported that about three-quarters of the subjects were conscious of their habitual chewing side, and this was discovered at the medical interview. Ogimito et al..$^{33}$ compared the reliability of the subjectivity of the habitual chewing side before and after mastication, and the results suggested that the medical interview after mastication was more reliable and more detectable than the one before.

The habitual chewing side in this study was found at the time of the medical interview before mastication, and the rate of agreement with the masticatory side was $95.2 \%$ in ND and $90.9 \%$ in $\mathrm{CD}$. These findings suggested that clenching the test food was a useful and easy method to determine the habitual chewing side.

\section{The occlusal contact area and occlusal force} Concerning the evaluation of Dental Prescale, it was reported that the occlusal contact area and occlusal force at the habitual chewing side was greater than the opposite one. ${ }^{43}$ In the present study, the number of agreements on the masticatory part was evaluated, and the ND were divided into ND-H and ND-L groups. CD was also examined. The occlusal contact area and occlusal force at the masticatory side was greater than the opposite one in ND-H, however, there were no differences in ND-L and CD. These results suggested that the subjects who did not have a regular masticatory part did not have a right or left difference regarding the occlusal contact area and occlusal force. And on the subjects who had a regular masticatory part, the occlusal contact area and occlusal force were greater than the opposite one.

\section{The center of the occlusal balance}

The center of the occlusal balance was calculated from the distribution of the occlusal contact area and occlusal force. In ND-H, the center of the occlusal balance tended to be toward the masticatory side. This finding was based on the idea that the chewing side would incline to the right or left, and the masticatory part could be easily decided in ND-H. On the other hand, the center of the occlusal balance converged toward the center in ND$\mathrm{L}$ and $\mathrm{CD}$. This finding indicated that it is difficult to determine whether the chewing side is on the right or left, and the masticatory part won't develop a tendency either way. Namely, these results suggested that there was a relationship among the number of agreements on the masticatory part, the center of the occlusal balance, the occlusal contact area, and occlusal force. 


\section{Conclusion}

This study investigated the masticatory part and the habitual chewing side using a wax cube and Dental Prescale in normal dentate subjects and complete denture wearers, and the following conclusions were obtained:

1. The temperature conditions of the test food did not influence the determination of the masticatory part.

2. The size of the test food did not influence the determination of the masticatory part.

3 . The percentage of agreement concerning the habitual chewing side and the masticatory part was $95.2 \%$ in normal dentate subjects and $90.9 \%$ in complete denture wearers.

4. The occlusal contact area and occlusal force of the masticatory side was greater than the opposite one in normal dentate subjects who had high agreement regarding the masticatory part $(p<$ 0.05). The occlusal contact area and occlusal force did not differ between the masticatory side and the opposite one in normal dentate subjects who had low agreement concerning the masticatory part and complete denture wearers.

5 . The center of the occlusal balance varied widely in normal dentate subjects who had high agreement regarding the masticatory part, and it converged toward the center in normal dentate subjects who had low agreement concerning the masticatory part and complete denture wearers.

In this study, it was suggested that the center of the occlusal balance was relevant to the habitual chewing side and the masticatory part. The determination of the masticatory part by clenching the test food and the evaluation of the occlusal contact area, occlusal force, and the center of the occlusal balance by Dental Prescale were useful to determine the habitual chewing side.

\section{References}

1. Manly RS, Braley LC. Masticatory performance and efficiency. J Dent Res 1950; 29: 448-462.

2. Hirai T, Ishijima T, Koshino $\mathrm{H}$ et al. Age-related change of masticatory function in complete denture wearers. Int J Prosthodont 1994; 7: 454-460.

3. Ishijima T, Hirai T, Koshino H et al. The relationship between salivary secretion rate and masticatory efficiency. J Oral Rehabil 2003; 31: 3-6.

4. Ishiwara T. Masticatory efficiency and particle size distribution of masticated raw rice. J Stomatol Soc
Jpn 1995; 22: 207-255. (in Japanese)

5. Tanaka A, Shiga H, Kobayashi Y. Quantitative evaluation of mandibular movement and masticatory muscular activities by analyzing the amount of glucose discharge during gummy jelly chewing. J Jpn Prosthodont Soc 1994; 38: 1281-1294.

6. Liedberg B, Öwall B. Oral bolus kneading and shaping measured with chewing gum. Dysphagia 1995; 10: 101-106.

7. Hayakawa I, Watanabe I, Hirano S et al. A simple method for evaluating masticatory performance using a color changeable chewing gum. Int J Prosthodont 1998; 11: 173-176.

8. Prinz JF. Quantitative evaluation of the effect of bolus size and number of chewing strokes on the intraoral mixing of a two-color chewing gum. J Oral Rehabil 1999; 26: 243-247.

9. Ikebe K. Reproducibility and accuracy in measuring masticatory performance using test gummy jelly. Prosthodont Res Pract 2005; 4: 9-15.

10. Kobayashi Y, Shiga H, Arakawa I et al. The effectiveness of measuring glucose extraction for estimating masticatory performance. Prosthodont Res Pract 2006; 5: 104-108.

11. Kato H, Furuki Y, Hasegawa S. Observations on the main occluding area in mastication. J Jpn Soc Stomatognath Funct 1996; 2: 119-127. (in Japanese)

12. Kato H, Hasegawa S, Yoshida K et al. Observations on the main occluding area in mastication-continuation - The relation with food impaction-. J Jpn Soc Stomatognath Funct 1999; 5: 125-133. (in Japanese)

13. Tokuda A, Kato H, Miura $\mathrm{H}$ et al. The main occluding area in consideration of the occlusal relation. $\mathrm{J}$ Jpn Soc Stomatognath Funct 2006; 13: 31-37. (in Japanese)

14. Peyron MA, Mioche L, Renon $\mathrm{P}$ et al. Masticatory jaw movement recordings - A new method to investigate food texture-. Food Qual Pref 1996; 7: 229237.

15. Peyron MA, Lassauzay C, Woda A. Effects of increased hardness on jaw movement and muscle activity during chewing of visco-elastic model foods. Exp Brain Res 2002; 142: 41-51.

16. Morita M, Kuroe K, Diniz P et al. Relationship between the masticatory jaw movement and the occlusal contact area, the maximum occlusal force and the alveolar bone mineral contact at the mandibular first molar region - Study with the unilateral mastication-. Orthod Waves 2002; 61: 22-30. (in Japanese)

17. Miyazaki J, Shiga H, Kobayashi Y. The reliability of evaluating masticatory function by masticatory movement analysis. Dent Jpn 2003; 39: 57-62.

18. Nakashima M, Okimoto K, Matsuo K et al. A study of masticatory ability in the elderly -A comparison between dentulous subjects and denture wearers-. 
J Jpn Prosthodont Soc 2003; 47: 779-786. (in Japanese)

19. Bhatka R, Throckmorton GS, Wintergerst AM et al. Bolus size and unilateral chewing cycle kinematics. Arch Oral Biol 2004; 49: 559-566.

20. Koshino H, Hirai T, Ishijima T et al. Quality of life and masticatory function in denture wearers. $\mathrm{J}$ Oral Rehabil 2006; 33:326-329.

21. Hasegawa S, Bando E. Encyclopedia of dental occlusion. Tokyo: Ishiyaku Publishers, Inc. 1997; 171. (in Japanese)

22. Stohler CS. A comparative electromyographic and kinesiographic study of deliberate and-habitual mastication in man. Arch Oral Biol 1986; 31: 669-678.

23. Liao FG, Shiozawa K, Yanagisawa K. Effects of changes in the physical property of test foods on the masseteric EMG, grindability of foods and the number of chewing strokes. Tsurumi Univ Dent J 1990; 16: 407-413.

24. Wilding RJC, Lewin A. A model for optimum functional human jaw movements based on values associated with a preferred chewing patterns. Arch Oral Biol 1991; 36: 519-523.

25. Kobayashi Y, Shiga H. The path of chewing movement before and after experimental occlusal interference. Front Med Biol Eng 1991; 3: 193-198.

26. Wilding RJC, Adams LP, Lewin A. Absence of association between a preferred chewing side and its area of functional contact in the human dentition. Arch Oral Biol 1992; 37: 423-428.

27. Kirverskari P, Alanen P. Right-left asymmetry of maximum jaw opening. Acta Odontol Scand 1989; 47: 101-103.

28. Sasaki M, Yoshikawa K, Hosoi T. A study on the chewing side preference in normal dentate subjects. J Masticat Health Soc 2002; 12: 43-48. (in Japanese)

29. Shiga H, Kobayashi Y, Arakawa I et al. Selection of food and chewing side for evaluating masticatory path stability. Odontology 2003; 91: 26-30.

30. Paphangkorakit J, Thothongkam N, Supanont N. Chewing-side determination of three food textures. J Oral Rehabil 2006; 33: 2-7.

31. Kurachi M, Ishigami H, Yokoyama Y et al. Expression of lateralized mastication index. J Jpn Prosth- odont Soc 1992; 36: 1026-1031. (in Japanese)

32. Hoogmartens MJ, Carbergh MAA. Chewing side preference in men. Electromyogr Clin Neurophysiol 1987; 27: 3-6.

33. Ogimoto T, Ogawa T, Umemoto G et al. Preferred chewing side detected by question and its association with other clinical findings. J Jpn Soc TMJ 1998; 10: 398-409. (in Japanese)

34. Sasaki M. A study of chewing side preference in complete denture wearers. Tsurumi Shigaku 2003; 29: 23-35. (in Japanese)

35. Sato H, Fueki K, Sueda S et al. A new and simple method for evaluating masticatory function using newly developed artificial test food. J Oral Rehabil 2003; 30: 68-73.

36. Sato H, Fueki K, Sato H et al. Validity and reliability of a newly developed method for evaluating masticatory function using discriminant analysis. $\mathrm{J}$ Oral Rehabil 2003; 30: 146-151.

37. Ichikawa T, Nagao K, Oka K. Consideration on complete denture prosthodontics of the future. Pract Prosthodont 2005; 38: 652-659. (in Japanese)

38. Yoshimura M, Fueki K, Garrett N et al. Influence of food platform width of mandibular removable partial denture on food mixing ability. J Oral Rehabil 2006; 33: 335-340.

39. Salleh NM, Fueki K, Garrett NR et al. Objective and subjective hardness of a test item used for evaluating food mixing ability. J Oral Rehabil 2007; 34: 174-183.

40. Fueki K, Yoshida E, Igarashi Y. Comparisons of masticatory movements between mixing ability test and masticatory performance test. Prosthodont Res Pract 2007; 6: 253-258.

41. Yoshida E, Fueki K, Igarashi Y. Association between food mixing ability and mandibular movements during chewing of a wax cube. J Oral Rehabil 2007; 34: 791-799.

42. Ueda N, Yuba N, Tanaka M et al. Investigation on the consciousness of masticatory laterality. J Jpn Prosthodont Soc 1991; 35: 708-714. (in Japanese)

43. Hayashi Y. A study on masticatory function and dental arch form - Relationship between habitual mastication and tooth position on dental arch-. Nippon Univ J Oral Sci 1995; 21: 223-234. (in Japanese) 